\title{
A Rare presentation of Diaphragmatic Eventration in an old man
}

\author{
Dr.Ramesh Kumar Korumilli ${ }^{1}$, Dr. Trimurty Rao Attili ${ }^{2}$, \\ Dr.Kapil Kishore Siddiraju ${ }^{3}$ \\ '(General Surgery, SVS Medical College/ Dr.NTR University of Health Sciences, India) \\ 2 (General Surgery,,ASRAM Medical College/Dr.NTR University of Health Sciences, India) \\ ${ }^{3}$ (General Surgery, SVS Medical College/ Dr.NTR University of Health Sciences, India)
}

Abstract : Diaphragmatic Eventration (DE) is a rare condition where the muscle is permanently elevated but retains its continuity and attachments to the costal margins. It is seldom symptomatic and often requires no treatment. We present a $65 y$ r old man with previously undiagnosed left sided congenital eventration who presented with predominantly abdominal symptoms and required elective plication

Keywords : Congenital diaphragmatic Eventration, Diaphragmatic Hernia

\section{INTRODUCTION}

Diaphragmatic Eventration is a pathologic condition defined by a permanent elevation of an immobile hemidiaphragm that cannot participate actively in respiration.Peripheral muscular attachments are normal,the diaphragmatic apertures are sealed normally and there is no interruption in the pleural/peritoneal layers as is seen with diaphragmatic hernias. DE may be a congenital anomaly caused by failure of muscularisation of the dome of a hemidiaphragm or it may be acquired as a result of dysfunction of the phrenic nerve. More common on left side and most commonly diagnosed in paediatric patients, the incidence in adulthood is low estimated to be between 1 in 10000 and 1 in 13000 .

\section{CASE SUMmary}

A $65 \mathrm{yr}$ old man presented with progressive symptoms of epigastric / left Hypochondric pain, fullness in the abdomen, belchings after taking food all of $11 / 2$ year duration. Also there was dyspnea on exertion. Examination revealed no abdominal pathology but bowel sounds heard higher upto the level of the nipple on left side. Also there were left supraclavicular fossa fullness and missed beats in ECG, cardiological evaluation was done.

Chest $\mathrm{x}$ ray disclosed elevated but intact left hemidiaphragm.(Figure 1) U/S chest showed displacement of spleen and small bowel into the lt thoracic cavity. The diagnosis of larger eventration of diaphragm was confirmed with a CTchest.[1]

He underwent a left posterolateral thoracotomy through the $7^{\text {th }}$ intercostalspace.[2]. Intraoperatively the thoracic cavity was considerably filled by a mass of abdominal organs covered with a thin, lax diaphragm. The Phrenic nerve appeared normal.The redundant diaphragmatic leaf was repaired by plication in two rows of sutures using 2-0 nylon. Each suture incorporated several cms of tissue in 2 to 3 equally space bites. All the sutures are placed parallel to the branches of the phrenic nerve taking care not to traumatize the underlying abdominal viscera.(Figure 2). After placation[3] the tissue became taut and thus incapable of flail. A thoracostomy tube was placed for pleural drainage. Patient was put on mechanical ventilatory support for one day, chest physiotherapy was given. Post op course was uneventful. Thoracostomy tube was removed on 6th post operative day.

Post operative chest $\mathrm{x}$ ray revealed the plicated diaphragm returning to almost normal position. Patient was remarkably relieved of his abdominal symptoms as well as dyspnoea and was discharged from our hospital on 12th post operative day. Pt came for postoperative follow up after 45 days. He was asymptomatic and doing well.[3] 
III. FIGURES AND TABLES

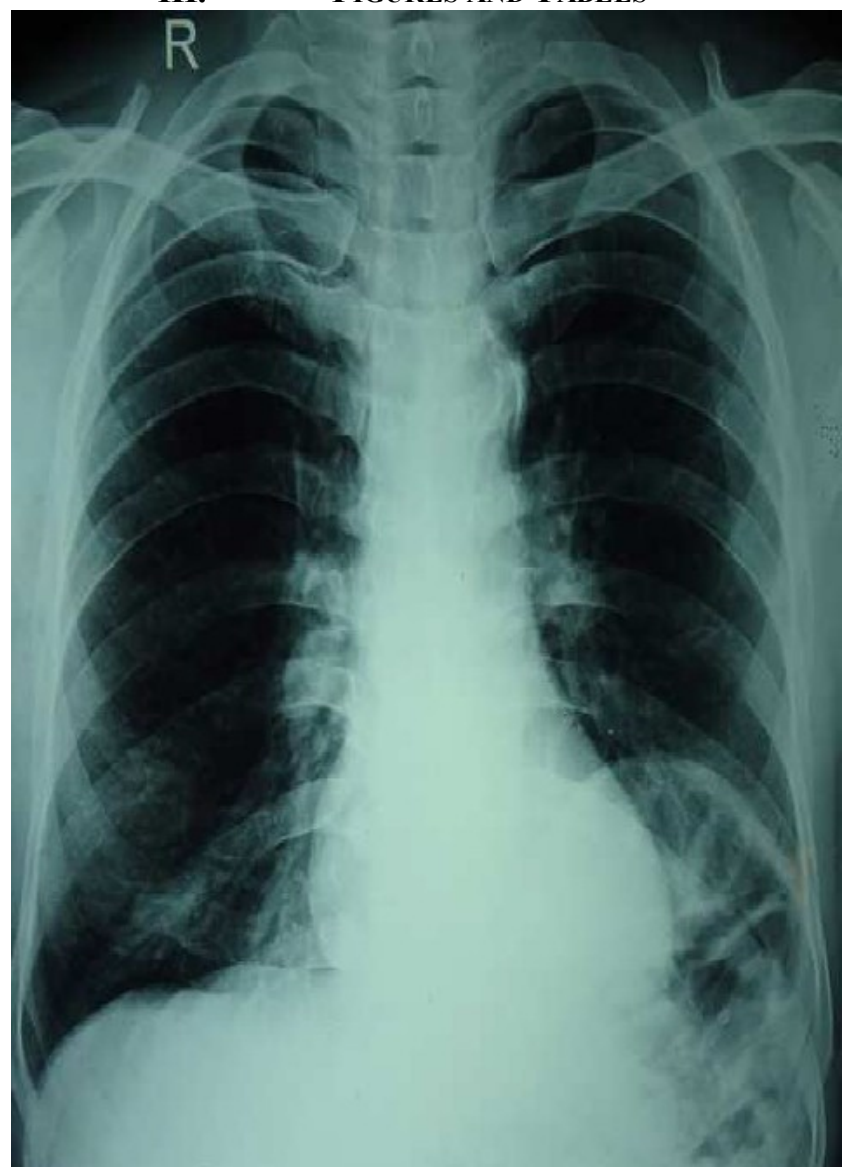

Figure 1: X-ray chest showing elevated left dome of diaphragm

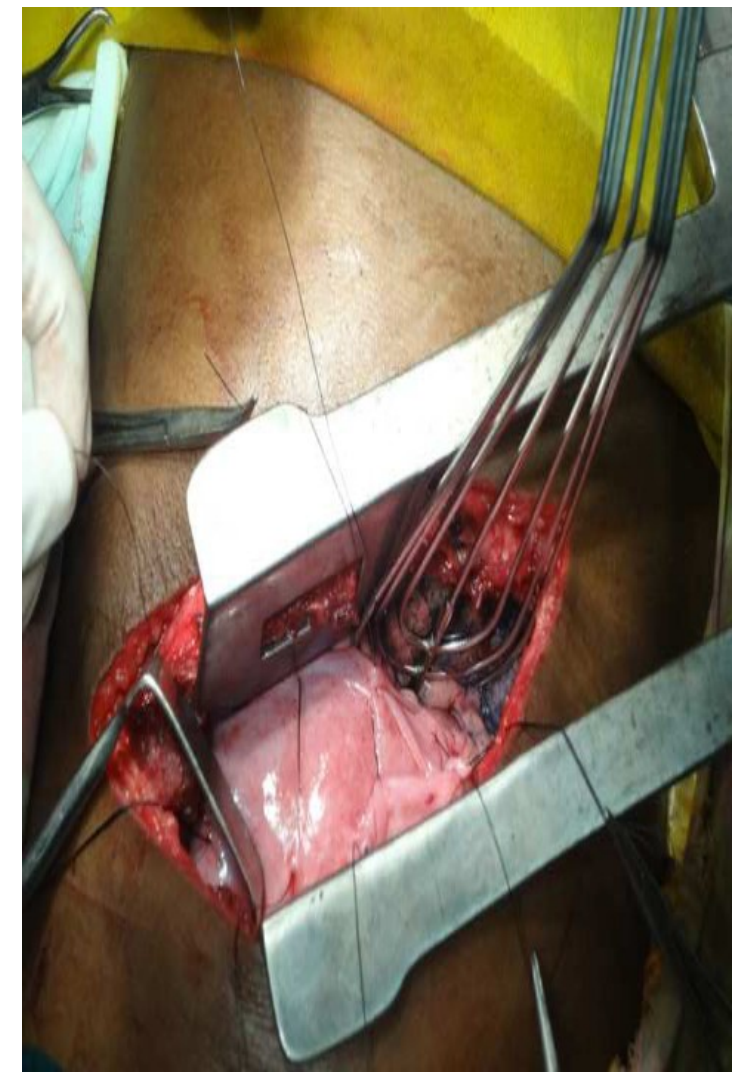

Figure 2: Thoracotomy wound showing placation of diaphragm 


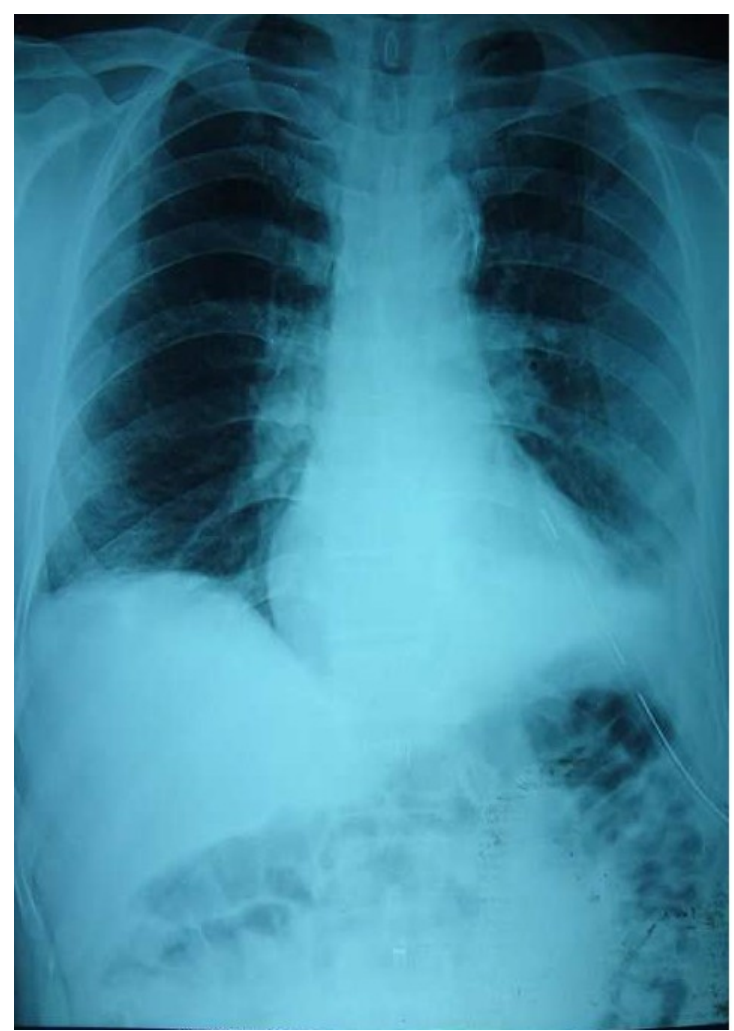

Figure 3: Post operative photograph with thorocotomy tube in-situ showing expanded lung

\section{CONCLUSION}

Most adults with congenital DE are asymptomatic and do not require surgical treatment, alternatively there may be respiratory symptoms (like breathlessness, chest pain cough) or abdominal symptoms ( like epigastric pain, dysphagia , dyspepsia, belchings and GER) associated with displacement of viscera into a large diaphragmatic eventration. Diagnosis is clear with intact but markedly elevated hemidiaphragm on chest radiograph and CT Chest is confirmatory. The goals of surgical theraphy should be a) to restore the diaphragm to a normal location within the involved hemithorax ,

b) to restore normal capacity to the hemithorax to allow lung growth in infants, children c) to restore normal visceral location in the abdomen d) to stabilize the mediastinum by eliminating paradoxical motion of the diaphragm. These goals can be achieved by usual open or laparoscopic

plication or resection of the redundant diaphragmatic tissue and establishing in its place a rigid diaphragmatic structure. We preferred plication to resection in the present case.

\section{REFERENCES}

[1]. Frederick C.Ryckman and Thomas H. Inge [ Eventration of the diagphragm ] Mastery of surgery 5th edition vo11 chapter 53

[2]. Diaphragmatic eventration.Groth SS, Andrade RS. Thorac Surg Clin. 2009 Nov;19(4):511-9. doi: 10.1016/j.thorsurg.2009.08.003.

[3]. Donzeau-Gouge GP,Personne C,Lechien J, et al.[Eventration of the diaphragm in the adult - 20 cases ] Ann Chir 1982;36: $87-90$. French 